\title{
Connecting model species to nature: predator-induced long-term sensitization in Aplysia californica
}

\author{
Maria J. Mason, Amanda J. Watkins, Jordann Wakabayashi, Jennifer Buechler, \\ Christine Pepino, Michelle Brown, and William G. Wright \\ Schmid College of Science, Chapman University, Orange, California 92866, USA
}

\begin{abstract}
Previous research on sensitization in Aplysia was based entirely on unnatural noxious stimuli, usually electric shock, until our laboratory found that a natural noxious stimulus, a single sublethal lobster attack, causes short-term sensitization. We here extend that finding by demonstrating that multiple lobster attacks induce long-term sensitization ( $\geq 24 \mathrm{~h}$ ) as well as similar, although not identical, neuronal correlates as observed after electric shock. Together these findings establish long- and short-term sensitization caused by sublethal predator attack as a natural equivalent to sensitization caused by artificial stimuli.
\end{abstract}

Sensitization, a simple form of learning that involves a nonspecific increase in defensive behavior after a novel or noxious stimulus, is observed in a wide variety of model species (Krasne and Glanzman 1986; Marcus et al. 1988; Rankin et al. 1990; Lockery and Kristan 1991; Frost et al. 1998; Crook et al. 2013). For more than four decades, studies of sensitization in the model species, Aplysia californica, have helped neurobiologists unravel the relationships between short- and long-term memory at the cellular and synaptic level (Pinsker et al. 1973; Martin et al. 1997; Sutton and Carew 2000; Carew and Sutton 2001; Bailey et al. 2004; Kandel 2004). These studies have established neural loci that are changed by long-term sensitization protocols and thereby contribute to the increased reflex withdrawal of sensitized animals (Frost et al. 1985; Castellucci et al. 1986; Walters 1987b; Cleary et al. 1998).

Most behavioral studies on sensitization in Aplysia have utilized electric shock or other artificial stimuli to induce sensitization (e.g., Mackey et al. 1987; Marcus et al. 1988; Glanzman et al. 1989; Walters 1987a,b, 1991; Sutton et al. 2002), leaving unanswered the question of what might cause sensitization in the natural ecology of Aplysia. Previously our laboratory showed that a single sublethal attack by the co-occurring California spiny lobster, Panulirus interruptus, caused short-term sensitization, very much like that produced after tail shock (Watkins et al. 2010). However, this study left two key questions unanswered. First, it did not test whether lobster attack could cause long-term sensitization with a memory of at least $24 \mathrm{~h}$. Furthermore, it presented no direct evidence that lobster attack could activate similar neural changes as observed after electric shock. In the present study, we tested for long-term sensitization after lobster attacks, and directly tested for attack-induced changes in neurons of the reflex circuit (Frost et al. 1985; Cleary et al. 1998).

We obtained individual Aplysia (50-80 g) from Alacrity Marine Biological Services and maintained them in large (400 L) tanks of artificial seawater (ASW, Natural Sea Salt Mix, Oceanic Systems Inc.) at $16^{\circ} \mathrm{C}$ in a 12 -h light-dark cycle. They were housed in aquaria separate from lobsters and used within $14 \mathrm{~d}$ of capture. California spiny lobsters (Panulirus interruptus, 80-90 $\mathrm{mm}$ carapace length, gender not determined) were either caught by hand from local waters (Long Beach, CA) or obtained from a local

\section{Corresponding author: wwright@chapman.edu}

Article is online at http://www.learnmem.org/cgi/doi/10.1101/Im.034330.114. seafood supplier (Santa Monica Sea Food) and maintained in isolated aquaria at $16^{\circ} \mathrm{C}$. We deprived lobsters of food for $2-6$ wk to encourage attack behavior. This deprivation caused no obvious weakness or change in behavior, other than more consistent attack responses.

We removed subject Aplysia from their home tanks prior to testing and placed them in 10-gal aquaria, freshly filled with ASW maintained at $16^{\circ} \mathrm{C}$. At least 30 min later, we elicited head and tail-mantle withdrawal reflexes with test stimuli, short duration 0.8-sec jets of water (Water Pik, Inc.) delivered alternately to the head and tail (order chosen randomly) of subject Aplysia from a distance of $2 \mathrm{~cm}$ to $3 \mathrm{~cm}$. The water-jet intensity of the test stimulus was set prior to all experiments to evoke a moderate 6- to 10-sec tail-mantle withdrawal reflex, and kept at that level for all stimuli of all subjects. We maintained a 2.5-min interval between head and tail test-stimuli (two tests for each reflex).

All reflexes were recorded on video. An experienced observer used the video recordings to score the duration of the withdrawal reflexes from the onset of the stimulus until the body began to relax (Marcus et al. 1988; Wright 1998; Watkins et al. 2010). For head withdrawal, this meant relaxation of the neck and parapodia. For tail-mantle withdrawal, this meant relaxation of the tail and the posterior part of the mantle, siphon, and parapodia. The observer had no knowledge of the sequence (pre or post) or treatment (attacked or control) of each scored reflex. Our previous research reporting that attack causes small microscopic lesions in the body wall of subject Aplysia was verified in the present study (V Zachary, pers. comm.). These lesions were too small to be visible to the observer of the withdrawal reflexes.

After two pretests, Aplysia were moved to a tank containing a lobster that had previously demonstrated attack behavior. Randomly assigned Aplysia were dropped in front of the lobster, thereby eliciting attack. Handling controls were dropped on the aquarium floor a safe distance from the lobster. Most lobster attacks persisted for $\sim 5-15 \mathrm{~min}$. We halted each attack when we saw clear biting behavior by the lobster, usually combined with enhanced balling up and profuse release of ink by the Aplysia.

(C) 2014 Mason et al. This article is distributed exclusively by Cold Spring Harbor Laboratory Press for the first 12 months after the full-issue publication date (see http://learnmem.cshlp.org/site/misc/terms.xhtml). After 12 months, it is available under a Creative Commons License (AttributionNonCommercial 4.0 International), as described at http://creativecommons. org/licenses/by-nc/4.0/. 
Lobster attacks were terminated by lifting the attacking lobster off the aquarium bottom, usually resulting in release of the sea hare. After each attack or handling session, each subject Aplysia was returned to its holding tank. Attacked Aplysia were treated with one, two, or four attacks. Attacks in the two-attack experiments were separated by $1-2 \mathrm{~h}$. Because lobsters could not be relied upon to perform four attacks per day, we were forced to give four attacks over $2 \mathrm{~d}$. This meant one to three attacks on the first day and one to three attacks on the second day, for a total of four attacks. Attacks on the same day were separated by 1-2 h; the first attack on the second day was $13-21 \mathrm{~h}$ after the last attack on the first day. Post-tests were delivered $24 \mathrm{~h}$ after the last attack. In the two-attack protocol, we used video recordings to measure the total time that the posterior versus anterior part of the subject Aplysia was held nearer the mouth of the lobster.

We tested for neurophysiological correlates (two measures of excitability, sensorimotor synapse strength, and motor neuron input resistance) of sensitization immediately after the post-tests for each four-attack experiment. We removed the ring ganglia of both attacked and control subject Aplysia, and made standard intracellular current clamp recordings of 10 tail sensory-neurons (SN) and two tail motor-neurons (MN) identified using conventional identification protocol (Walters et al. 1983). The person performing each dissection and ensuing neurophysiology experiment was ignorant of the treatment (attacked or handling control) received by that animal. We first impaled a tail MN, and tested its input resistance by injecting enough current to hyperpolarize the cell by $10-20 \mathrm{mV}$. We kept the MN hyperpolarized by 40 $\mathrm{mV}$ from resting potential to prevent it from spiking. We then recorded from five different SNs. For each SN, we waited 2-5 min after impalement to activate action potentials with depolarizing intracellular current. If the initial action potential was less than $40 \mathrm{mV}(\sim 10 \%$ of recorded cells) we rejected it and impaled a new SN. For every SN, we measured the threshold current to activate a single AP, and whether that SN's AP caused an excitatory postsynaptic potential in the $\mathrm{MN}$; if it did, we measured the amplitude of that EPSP. For the first three SNs we also counted the number of SN action potentials produced by current pulses $(200 \mathrm{msec}$, DC) of $0.1,1.0,2.0$, and 3.0 nA. After these tests of firing properties and synaptic strength, we recorded from a second MN and tested an additional five SNs in the same way. From these measurements each animal produced a single mean threshold based on 10 SNs, a mean number of action potentials in response to each of the four different current inputs in six SNs, a mean synaptic strength, based on 10 SNs and two MNs, and a mean MN input resistance, based on two MNs. We also calculated synaptic current by dividing each EPSP by its MN input resistance (Cleary et al. 1998).

We used R (an open-source statistics program, R Core Team 2013) for all data analyses. To reduce variation, we excluded experiments in which pretests (head or tail-mantle withdrawal) were not within $50 \%$ of one another (10 of 49 experiments). We averaged the duration of each animal's withdrawal reflexes before (pretest) and after (post-test) being attacked, or handled without attack. All bar graphs show means \pm standard error of means. We considered that sensitization was demonstrated when attacked subjects increased their reflex responding relative to their own pre-test reflexes (paired $t$-test), and when that increase was greater than that of their matched handling controls (paired $t$-tests). We also used a paired $t$-test to compare the amount of time attacking lobsters held subject Aplysia with the tail versus head toward or in the mouth. To compare overall sensitization between one-, two-, and four-attack experiments, we calculated an overall measure of sensitization by averaging the percent increase in response duration of head and tail withdrawal of each experiment's attacked animal minus the same measure in that experiment's handling control. We performed an ANOVA on this overall "sensitization index" from all three sets of experiments, followed by Tukey HSD post-hoc tests comparing the three sets to each other. We used paired $t$-tests to test for significant neurophysiological differences (SN-MN EPSP amplitude, SN threshold) between attacked Aplysia versus their handling controls. To test for effects of attack on number of SN APs measured at four different intracellular depolarizing currents, we used a two-way mixed repeated-measures ANOVA. All $\alpha$ probabilities are two-tailed.

As shown in Figure 1A, we observed no significant long-term sensitization in either head or tail-mantle withdrawal $24 \mathrm{~h}$ after a single lobster attack. This was exactly the same attack protocol that produced robust sensitization 30-60 min after lobster attack in our previous research (Watkins et al. 2010).
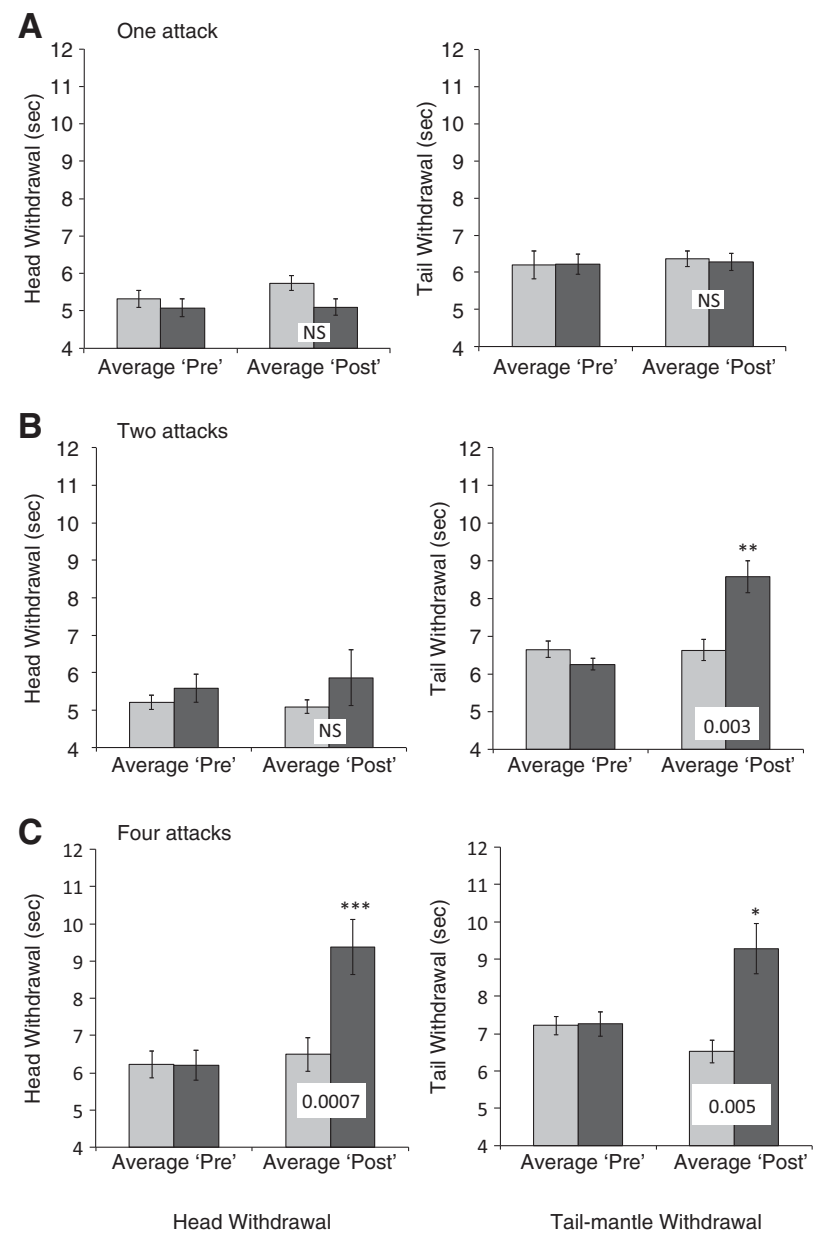

Figure 1. Long-term sensitization of withdrawal reflexes in Aplysia $24 \mathrm{~h}$ after one, two, or four lobster attacks. Shown are average ( \pm standard error of means) withdrawal reflexes (seconds; head withdrawal left side, tail withdrawal right side) before (Average Pre) and after (Average Post) lobster attack(s). Light bars show reflexes of handling controls, dark bars reflexes of attacked sea hares. Note that that the $y$-axis begins at $4 \mathrm{sec}$. Asterisks $\left.\left(\left[{ }^{*}\right] \leq 0.05,{ }^{* *}\right] \leq 0.01,\left[{ }^{* * *}\right] \leq 0.001\right)$ indicate $P$-values for repeated measures $t$-test of post vs. pre-attack reflexes. Values across Average Post histograms indicate probabilities from paired $t$-test of the change in reflex in attacked vs. control animals ([NS] not significant at $P=0.05)$. (A) One lobster attack $(N=14)$ failed to produce long-term sensitization. $(B)$ Two lobster attacks $(N=14)$ produced long-term sensitization of tail-mantle withdrawal, but not of head withdrawal. Sensitization in tail-mantle withdrawal was not significantly different from that in head withdrawal $(P=0.15)$. (C) Four lobster attacks $(N=$ 11) produced significant long-term sensitization in both head and tailmantle withdrawal reflexes. 
By contrast, two lobster attacks sufficed to cause long-term sensitization, at least in the tail-mantle withdrawal reflex, and nearly did so in the head withdrawal reflex (Fig. 1B). We analyzed the attack videos for evidence that the posterior region of Aplysia may have received more trauma than did the anterior. We found that attacking lobsters held the posterior part of their Aplysia prey in or near their mouth $(340 \pm 50 \mathrm{sec})$ nearly four times longer than they did the anterior part $(94 \pm 21$; repeated measures $t$-test, $P \leq 0.001$, data not shown).

Four lobster attacks significantly sensitized both head and tail-mantle withdrawal reflexes (Fig. 1C). In order to test whether sensitization was related to the number of attacks, we combined the data from each of the three (one, two, and four attack) experiments into a single sensitization index. This index was strongly related to the number of lobster attacks administered (Fig. 2).

After the four-attack experiments, we tested SNs of Aplysia for decreased firing threshold and spike-frequency adaptation, two neuronal correlates of SN excitability. These two measures together suggested similar sensitization-related changes as observed after electric shock. First, the threshold current required to elicit a single action potential in tail SNs was significantly lower in attacked Aplysia than in handling controls (Fig. 3A,B). Second, SNs of attacked Aplysia appeared to show more spikes across each of the four current pulses (Fig. 3C) than did SNs of control Aplysia, suggesting reduced spike-frequency adaptation. However, repeated measures ANOVA on these latter data was just short of two-tailed statistical significance $\left(F_{(1,72)}=3.72, P=0.058\right)$.

A second class of neuronal correlate is the strength of the monosynaptic EPSP from tail SNs to pedal MNs. Unlike the results of previous studies with electric shock (Frost et al. 1985; Walters 1987b; Cleary et al. 1998), the sensorimotor synapse strength of attacked Aplysia (mean EPSP amplitude $=1.3 \pm 0.5 \mathrm{mV}$ ) was not significantly different from that of handling controls $(1.7 \pm 0.6$; attacked, NS). Synaptic current was also similar in both groups (control $0.04 \pm 0.02 \mathrm{nA}$; attacked $0.06 \pm 0.03 \mathrm{nA}$; NS). Input resistances of MNs were also similar between attacked and control Aplysia (attacked 57.5 $\pm 11.8 \mathrm{M} \Omega$ vs. control $60.0 \pm 12.9 \mathrm{M} \Omega$ ).

Together, these observations, combined with our earlier study on short-term sensitization, establish attack by the California spiny lobster, Panulirus interruptus, as an ecologically relevant natural noxious stimulus that can produce both short-term

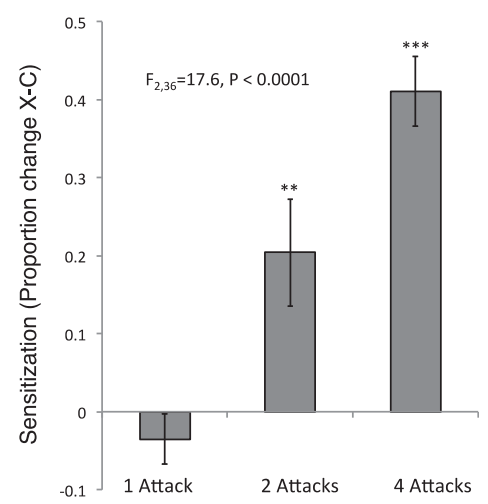

Figure 2. Combining withdrawal reflexes across treatments indicates that long-term sensitization increases with increasing numbers of lobster attacks. Shown are the differences in overall proportion increase (average of head and tail-mantle withdrawal) between each experimental and nonattacked control. One-way ANOVA of the three groups $(N=14$, 14 , and 11 ) is highly significant and all three means are significantly different from each other (Tukey HSD test). Asterisks above each histogram indicate $\left([* *] \leq 0.01,\left[{ }^{* * *}\right] P \leq 0.001\right)$ probabilities derived from a single sample $t$-test vs. the null hypothesis of no sensitization (zero difference between experimental and control).
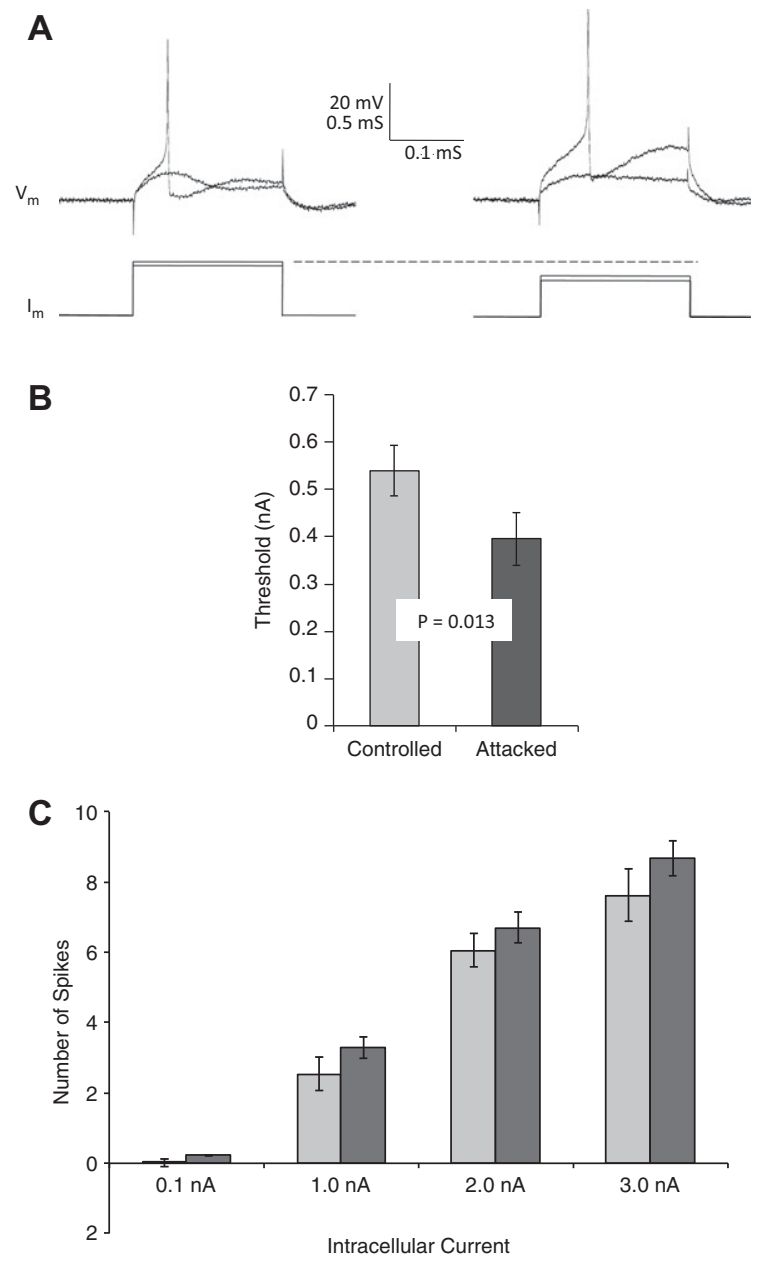

Figure 3. Overall excitability of sensory neurons, as measured by spike threshold and number of spikes produced by a depolarizing pulse, was increased after lobster attack. $(A)$ Firing threshold: Superimposed traces from two representative threshold experiments show intracellular membrane potential $\left(V_{\mathrm{m}}\right)$ and intracellular current $\left(I_{\mathrm{m}}\right)$ for barely subthreshold and a slightly larger, suprathreshold, current pulse. Representative SN from control Aplysia is shown on the left, attacked Aplysia on the right. (B) Average threshold was significantly (repeated measures $t$-test, $N=$ 11,$11 ; P=0.013$ ) lower in sensory neurons of attacked (dark bar) subjects than those of handling controls (light bar). (C) Number of action potentials produced by a 500-msec depolarizing current pulse (current indicated on $x$-axis), although trending higher in attacked animals (dark bars) than handling controls (light bars) across four stimulus-current levels, was not significantly different ( $\alpha=0.05$, two-tailed; repeated measures ANOVA, $\left.F_{(1,72)}=3.72, P=0.058\right)$.

(Watkins et al. 2010) and long-term (present study) sensitization. The behavioral experiments of the present study indicate that long-term sensitization induced by lobster attack shares important features with sensitization caused by electric shock. First, like electric shock, one lobster attack is not sufficient to produce long-term sensitization (Sutton and Carew 2000; Carew and Sutton 2001; Philips et al. 2007). Second, multiple shocks (two or four) do cause long-term sensitization. Third, increased number of attacks produces increased amplitude of sensitization (Frost et al. 1985; Marcus et al. 1988; Sutton and Carew 2000; Carew and Sutton 2001; Bailey et al. 2004; Philips et al. 2007).

Previous research on long-term sensitization after multiple strong electric shocks established several different manifestations of increased SN excitability (Scholz and Byrne 1987; Walters 
1987b; Walters et al. 1991; Cleary et al. 1998), including reduced threshold, increased number of spikes for a given intracellular or peripheral stimulus, and reduction in specific $\mathrm{K}^{+}$currents. These changes are similar to those observed in the present study $24 \mathrm{~h}$ after lobster attack, i.e., significantly decreased firing thresholds and a nonsignificant increase in number of spikes fired by a depolarizing current.

Unlike our results with SN excitability, our investigation of synaptic strength did not provide evidence of a neuronal correlate. Previous investigators (Frost et al. 1985; Walters 1987b; Cleary et al. 1998) found that SN-MN synapses were significantly strengthened after long-term sensitization caused by multiple electric shocks. Our measurements of synapse strength after four lobster attacks did not detect such a strengthening, raising the possibility of mechanistic differences between the effects of electric shock versus those of lobster attack.

One potential reason for such a difference is the possibility that lobster attack causes severe damage to peripheral tissue, activating peripheral mechanisms of plasticity particularly effectively. In our present (V Zachary, pers. comm.) and previous (Watkins et al. 2010) studies, we observed microscopic lesions in the body wall of attacked Aplysia similar to those observed after damaging cuts (Billy and Walters 1989). Peripheral plasticity after damaging noxious stimuli has been observed in other invertebrates (Crook et al. 2013), as well as vertebrates (Lamotte et al. 1991; Coderre et al. 1993; Millan 1999; Gold and Gebhart 2010), and this activation of peripheral mechanisms can also contribute to increased excitability of central SNs (Walters and Ambron 1995; Gasull et al. 2005). Furthermore, because SNs in and near the site of damage fire extensively during the damaging stimuli, they may undergo "activity dependent extrinsic modulation" (Walters 1987a,b, 1991; Billy and Walters 1989; Walters et al. 1991, 1995; Gasull et al. 2005), further increasing their excitability. Thus, perhaps lobster attack activates these peripheral processes more than it does the central synaptic mechanisms that have been the focus of a great deal of recent research (Martin et al. 2000; Kandel 2004). Unfortunately, there is very little evidence that lobster attack damages the periphery any more than does electric shock, which also produces lesions of Aplysia body wall (Walters 1987a; MJ Mason, pers. comm.; WG Wright, pers. comm.).

We thus favor the hypothesis that synaptic strengthening, regardless of whether it is caused by electric shock or lobster attack, is a relatively modest neuronal correlate that is simply more difficult to detect. Frost et al. (1985) observed the effect $(P<0.05)$ only after a large number of experiments $(N=90)$, and winnowing their experimental subjects to those $60 \%$ that showed maximum sensitization. Cleary et al. (1998) utilized a within-subject design that afforded them greatly increased experimental power. Proliferation of synaptic active zones (a likely physical mechanism for synapse strengthening) (Bailey and Chen 1983) in long-term sensitized Aplysia was only observed after 16-20 noxious experiences (vs. a maximum of four in the present study) and required strong winnowing of an unstated percent. Neither increased training trials, nor within-animal experimental design was available in the present study, inasmuch as lobster attack is not as reliable, nor anatomically precise, as is electric shock. Overall then, we favor the hypothesis that long-term synaptic strengthening is a relatively modest correlate of long-term sensitization, making it very difficult to detect with live attacking lobsters as the noxious stimulus. The alternative hypothesis, that something about lobster attack fails to activate processes activated by electric shock, is still a viable possibility that can only be addressed by utilizing more test subjects and more attacks per subject.

Consideration of the predator-prey relationship between sea hares and lobsters raises several ecological/evolutionary questions. First, do lobsters, which must be deprived of food in the lab- oratory to elicit attack on the chemically protected Aplysia, ever attack Aplysia in nature? The answer to this question is yes, but only in marine reserves, where large numbers and sizes of lobsters create more competition for food (JS Berriman, MC Kay, DC Reed, pers. comm.; JS Berriman, MC Kay, DC Reed, A Rassweiler, DA Goldstein, WG Wright, in prep.), presumably mimicking the original predator-prey relationship of Aplysia and lobsters. Second, do individual Aplysia ever survive lobster attack? In both laboratory and field observations, lobsters display a range of attack intensities, from immediate consumption to a more timid probing and release of the sea hare, often in response to the prey's release of defensive secretions (WG Wright, pers. obs.; Nolen et al. 1995; Nolen and Johnson 2001; Kicklighter et al. 2005; Derby 2007). Thus, sublethal attack is common in the predator-prey relationship of these two species. Third, what is the adaptive advantage of sensitization after lobster attack? The answer to this last question is not clear. One possibility is that multiple lobster attacks are a signal of increased risk of future attacks, an environment in which any defensive behavior will increase survival. A second, not mutually exclusive, hypothesis is that enhanced defensive withdrawal may protect injured tissue from further damage and facilitate healing (Walters and Ambron 1995; Walters and Moroz 2009).

To conclude, more than 40 years of focused work on the synaptic, cellular, and subcellular mechanisms of learning in Aplysia have revealed an intricate web of mechanisms that transform short-term into long-term memory (Martin et al. 1997; Sutton and Carew 2000; Carew and Sutton 2001; Bailey et al. 2004; Kandel 2004; Philips et al. 2007). Yet, until now, there was no evidence that any natural stimulus could produce long-term sensitization in Aplysia. Together with our previous work on short-term sensitization (Watkins et al. 2010), we have now documented, at both behavioral and neurophysiological levels, a natural ecological effector of sensitization in Aplysia, thereby excluding the possibility that strong electric shock is an entirely irrelevant noxious stimulus. Instead, we have shown that such shock has a natural equivalent in lobster attack that produces many of the behavioral and neurobiological effects that form the basis of modern models of learning and memory.

\section{Acknowledgments}

This research was supported by the National Science Foundation, Division of Integrative Organismal Systems (IOS-0721800). We thank Virginia Zachary for assistance and Cyril Rakovski for assistance with statistical analyses.

\section{References}

Bailey CH, Chen M. 1983. Morphological basis of long-term habituation and sensitization in Aplysia. Science 220: 91-93.

Bailey CH, Kandel ER, Si KS. 2004. The persistence of long-term memory: a molecular approach to self-sustaining changes in learning-induced synaptic growth. Neuron 44: 49-57.

Billy AJ, Walters ET. 1989. Long-term expansion and sensitization of mechanosensory receptive fields in Aplysia support an activity dependent model of whole-cell sensory plasticity. J Neurosci 9: $1254-1262$.

Carew TJ, Sutton MA. 2001. Molecular stepping stones in memory consolidation. Nat Neurosci 4: 769-771.

Castellucci VF, Frost WN, Goelet P, Montarolo PG, Schacher S, Morgan JA, Blumenfeld H, Kandel ER. 1986. Cell and molecular analysis of long-term sensitization in Aplysia. J Physiol (Paris) 81: 349-357.

Cleary LJ, Lee WL, Byrne JH. 1998. Cellular correlates of long-term sensitization in Aplysia. J Neurosci 18: 5988-5998.

Coderre TJ, Katz J, Vaccarino AL, Melzack R. 1993. Contribution of central neuroplasticity to pathological pain: review of clinical and experimental evidence. Pain 52: 259-285.

Crook RJ, Hanlon RT, Walters ET. 2013. Squid have nociceptors that display widespread long-term sensitization and spontaneous activity after bodily injury. J Neurosci 33: 10021-10026. 
Derby CD. 2007. Escape by inking and secreting: Marine molluscs avoid predators through a rich array of chemicals and mechanisms. Biol Bull 213: $274-289$.

Frost WN, Castellucci VF, Hawkins RD, Kandel ER. 1985. Mono-synaptic connections made by the sensory neurons of the gill-withdrawal and siphon-withdrawal reflex in Aplysia participate in the storage of long-term memory for sensitization. Proc Natl Acad Sci 82: 8266-8269.

Frost WN, Brandon CL, Mongeluzi DL. 1998. Sensitization of the Tritonia escape swim. Neurobiol Learn Mem 69: 126-135.

Gasull XX, Liao G, Dulin MF, Phelps C, Walters ET. 2005. Evidence that long-term hyperexcitability of the sensory neuron soma induced by nerve injury in Aplysia is adaptive. J Neurophysiol 94: 2218-2230.

Glanzman DL, Mackey SL, Hawkins RD, Dyke AM, Lloyd PE, Kandel ER. 1989. Depletion of serotonin in the nervous system of Aplysia reduces the behavioral enhancement of gill withdrawal as well as the heterosynaptic facilitation produced by tail shock. J Neurosci 9: 4200-4213.

Gold MS, Gebhart GF. 2010. Nociceptor sensitization in pain pathogenesis. Nat Med 16: $1248-1257$.

Kandel ER. 2004. The molecular biology of memory storage: a dialog between genes and synapses. Biosci Rep 24: 475-522.

Kicklighter CE, Shabani S, Johnson PM, Derby CD. 2005. Sea hares use novel antipredatory chemical defenses. Curr Biol 15: 549-554.

Krasne FB, Glanzman DL. 1986. Sensitization of the crayfish lateral giant escape reaction. J Neurosci 6: 1013-1020.

Lamotte RH, Shain CN, Simone DA, Tsai EFP. 1991. Neurogenic hyperalgesia: psychophysical studies of underlying mechanisms. J Neurophysiol 66: 190-211.

Lockery SR, Kristan WB. 1991. Two forms of sensitization of the local bending reflex of the medicinal leech. J Comp Physiol A 168: 165-177.

Mackey SL, Glanzman DL, Small SA, Dyke AM, Kandel ER, Hawkins RD. 1987. Tail shock produces inhibition as well as sensitization of the siphon-withdrawal reflex of Aplysia: possible behavioral role for presynaptic inhibition mediated by the peptide Phe-Met-Arg-Phe-NH2. Proc Natl Acad Sci 84: 8730-8734.

Marcus EA, Nolen TG, Rankin CH, Carew TJ. 1988. Behavioral dissociation of dishabituation, sensitization and inhibition in Aplysia. Science 241: $210-213$

Martin KC, Michael D, Rose JC, Barad M, Casadio A, Zhu HX, Kandel ER. 1997. MAP kinase translocates into the nucleus of the presynaptic cell and is required for long-term facilitation in Aplysia. Neuron 18: 899-912.

Martin SJ, Grimwood PD, Morris RGM. 2000. Synaptic plasticity and memory: an evaluation of the hypothesis. Annu Rev Neurosci 23: $649-711$

Millan MJ. 1999. The induction of pain: an integrative review. Prog Neurobiol 57: 1-164.

Nolen TG, Johnson PM. 2001. Defensive inking in Aplysia spp: multiple episodes of ink secretion and the adaptive use of a limited chemical resource. J Exp Biol 204: 1257-1268.
Nolen TG, Johnson PM, Kicklighter CE, Capo T. 1995. Ink secretion by the marine snail Aplysia californica enhances its ability to escape from a natural predator. J Comp Phys A 176: 239-254.

Philips GT, Tzvetkova EI, Carew TJ. 2007. Transient mitogen-activated protein kinase activation is confined to a narrow temporal window required for the induction of two-trial long-term memory in Aplysia. J Neurosci 27: 13701-13705.

Pinsker HM, Hening WA, Carew TJ, Kandel ER. 1973. Long-term sensitization of a defensive withdrawal reflex in Aplysia. Science 182: 1039-1042.

Rankin CH, Beck CDO, Chiba CM. 1990. Caenorhabditis elegans: A new model system for the study of learning and memory. Behav Brain Res $\mathbf{3 7}$ : 89-92.

R Core Team. 2013. A language and environment for statistical computing. R Foundation for Statistical Computing, Vienna, Austria.

Scholz KP, Byrne JH. 1987. Long-term sensitization in Aplysia. Biophysical correlates in tail sensory neurons. Science 235: 685-687.

Sutton MA, Carew TJ. 2000. Parallel molecular pathways mediate expression of distinct forms of intermediate-term facilitation at tail sensory-motor synapses in Aplysia. Neuron 26: 219-231.

Sutton MA, Ide J, Masters SE, Carew TJ. 2002. Interaction between amount and pattern of training in the induction of intermediate- and long-term memory for sensitization in Aplysia. Learn Mem 9: 29-40.

Walters ET. 1987a. Site-specific sensitization of defensive reflexes in Aplysia: a simple model of long-term hyperalgesia. J Neurosci 7: 400-407.

Walters ET. 1987b. Multiple sensory neuronal correlates of site-specific sensitization in Aplysia. J Neurosci 7: 408-417.

Walters ET. 1991. A functional, cellular, and evolutionary model of nociceptive plasticity in Aplysia. Biol Bull 180: 241-251.

Walters ET, Ambron RT. 1995. Long-term alterations induced by injury and by 5-HT in Aplysia sensory neurons: convergent pathways and common signals. Trends Neurosci 18: 137-142.

Walters ET, Moroz LL. 2009. Molluscan memory of injury: evolutionary insights into chronic pain and neurological disorders. Brain Behav Evol 74: 206-218.

Walters ET, Byrne JH, Carew TJ, Kandel ER. 1983. Mechanoafferent neurons innervating the tail of Aplysia. I. Response properties and synaptic connections. J Neurophysiol 50: 1522-1542.

Walters ET, Alizadeh H, Castro GA. 1991. Similar neuronal alterations induced by axonal injury and learning in Aplysia. Science 253: $797-799$

Watkins AJ, Goldstein DA, Lee LC, Pepino CJ, Tillett SL, Ross FE, Wilder EL, Zachary VA, Wright WG. 2010. Lobster attack induces sensitization in the sea hare, Aplysia californica. J Neurosci 30: 11028-11031.

Wright WG. 1998. Evolution of nonassociative learning: behavioral analysis of a phylogenetic lesion. Neurobiol Learn Mem 69: 326-337.

Received January 12, 2014; accepted in revised form June 12, 2014. 


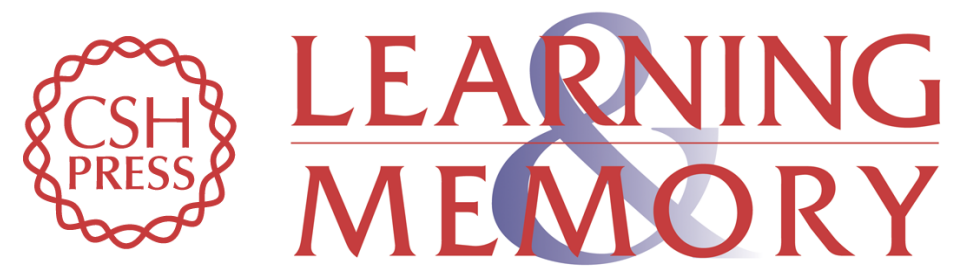

\section{Connecting model species to nature: predator-induced long-term sensitization in Aplysia californica}

Maria J. Mason, Amanda J. Watkins, Jordann Wakabayashi, et al.

Learn. Mem. 2014, 21:

Access the most recent version at doi:10.1101/lm.034330.114

References This article cites 41 articles, 18 of which can be accessed free at: http://learnmem.cshlp.org/content/21/8/363.full.html\#ref-list-1

Creative This article is distributed exclusively by Cold Spring Harbor Laboratory Press for the Commons License first 12 months after the full-issue publication date (see

http://learnmem.cshlp.org/site/misc/terms.xhtml). After 12 months, it is available under a Creative Commons License (Attribution-NonCommercial 4.0 International), as described at http://creativecommons.org/licenses/by-nc/4.0/.

Email Alerting Receive free email alerts when new articles cite this article - sign up in the box at the Service top right corner of the article or click here. 